\title{
Su'ifefiloi: A Samoan Methodology for Transdisciplinary Theorising in Cosmopolitan Worlds
}

\author{
Lana Lopesi
}

\begin{abstract}
As universities make moves toward transdisciplinary research, su'ifefiloi, the Samoan practice of sewing different parts together, offers a culturally grounded research methodology for transdisciplinary theorising by Pacific scholars. Pacific transdisciplinary actors working on theory within the cosmopolitan context requires, as Gordon writes, a willingness to go beyond discipline areas to produce knowledge. Theory work, as this paper argues, requires transdisciplinarity and a willingness to go beyond one's discipline area to extend knowledge. Working with Tuhiwai Smith's assertion on the importance of theory, this paper discusses the usefulness of su'ifefiloi in recent turns to transdisciplinarity.
\end{abstract}

\section{Introduction}

The methodology of su'ifefiloi, which makes use of the process of selecting, then sewing or stitching various flowers to create an ula or flower garland, which combines many different parts to create something new. The process of selecting and combining in a culturally cognisant way is one that all Pacific researchers today have to contend with, given the cosmopolitan worlds we all now inhabit. Pushing against romantic tendencies in Pacific research methodologies, this paper discusses how su'ifefiloi can also be understood through the metaphor of the ula lole (or lolly lei) ${ }^{1}$ : it offers a cosmopolitan take on su'ifefiloi necessary for today's cosmopolitan realities, able to hold the complex and uncompromised story work of both our cosmopolitan research, and our full selves as researchers.

The world around us is typified by a particular kind of globality (in a pre-Covid era), enabled by a combination of air travel, the global economy, and digital technology. This global character enables countless situated ideas, cultures, and references to be part of global flows, which are then accessed from any number of locales within seconds. This creates the footing for a particular kind of cosmopolitan character of life which impacts - and is simultaneously impacted by - Pacific life. Many Pacific researchers today find themselves across any number of specialist disciplines conducting Pacific-centred research from diverse disciplinary homes in the cosmopolitan cities and centres that they live in. Thus, Pacific research, while rooted culturally, is also made within these cosmopolitan spaces, with the influences of cosmopolitan flows. Conversely, Pacific academics circulating the globe to present at conferences (or in today's reality, navigating the online conference) also place the academics and their scholarship as actors within a cosmopolitan reality. This situates Pacific scholarship relationally to many other traditions of thinking and being.

This cosmopolitan character of life, I argue, requires theoretical work to engage in a kind of transdisciplinarity: an approach to research that moves beyond the silos of disciplinary areas that rely on their own notions of truth, requiring instead imaginative work. This is work that aims to "transcend the culture of the academy," as "disciplines work through each other" extend knowledge. This mode of transdisciplinarity enables the development of Pacific theoretical work, making the researchers Pacific transdisciplinary actors working on theory with the cosmopolitan context. This work, however, requires a methodological approach to make sense of the productive and generative chaos. In this paper I discuss how the Samoan 
methodology of su'ifefiloi offers one such approach for transdisciplinary theorising within cosmopolitan worlds.

\section{On Cosmopolitanism}

In my doctoral research, which examined the work of a digital native generation of Pacific artists and their art made between 2012 and 2020, it became clear that to understand their artwork and art-making practices, I would also need to understand their lived experiences. ${ }^{4}$ Through talanoa with a number of artists and arts workers, it was revealed that there was no longer an affinity with the term diaspora as a marker of identity. This was for a couple of reasons. One, the way in which the diaspora had an overemphasis on the notion of displacement, assimilation, and non-belonging that did not match these artists' selfperceptions. Two, this generation of Moana people are not bound to the home-and-host binary of diaspora, but rather are active participants in global worlds, not lost or displaced, but comfortable in their complexities.

James Clifford writes that the language of diaspora is used by "displaced peoples who feel (maintain, revive, invent) a connection with a prior home." ${ }^{5} \mathrm{He}$ notes the connection felt to the prior home has to be strong enough to resist assimilation and forgetting. The lived separation and entanglement of living here and remembering there becomes a key characteristic of diaspora, together with a need to both accommodate and to resist the host country's norms. Consequently, diasporic peoples balance "a complex combination of resistances and negotiations." ${ }^{\prime 6}$ As Clifford emphasises, negative features of displacement and contestationor "identity issues" as you may hear it discussed colloquially - are emphasised in the literature on diaspora because positive articulations of diasporic life do not fit in the colonial imaginary. ${ }^{7}$

Diaspora also speaks specifically to notions of host and home, a binary relationship between two places. However, the artists I spoke with did not necessarily feel an affinity to that notion but held more complicated positionalities beyond the binaries of home island and host country, of here and there. They were instead identities that were both rooted (in place and ancestry) and routed expansively (physically and digitally). This follows what native studies scholar Vicente Diaz advocated for: expansiveness without "sacrificing specificity, ways that ground indigeneity without essentialist insularities," that "might be nudged mindfully into potent forms of decolonized indigenous futures." 8

Cosmopolitanisms have been well addressed by scholars for years now, who have often found ways to rehabilitate and rework cosmopolitanism to understand the contemporary situation of any given moment. In 2010, Teresia Teaiwa commented that "when we think about cosmopolitanism, there's a way in which it's unavoidably tinged by a certain elite privilege. Now, globalising - and, ironically, even some neoliberal economic restructuring - processes have helped to make cosmopolitanism and regionalism something that is much less an elite privilege than it used to be." ${ }^{\prime 9}$ Cosmopolitanism, as I subscribe to it, is not about the flattening and universalist tendencies of some early cosmopolitan proponents, but rather, has an implicit sense of relationality arising from this global character. This type of cosmopolitan project is about "a pluri-versal world order built upon and dwelling on the global borders of modernity/coloniality" or, in other words, a cosmopolitan localism. ${ }^{10}$ This kind of cosmopolitanism is very closely aligned to notions of roots and routes, which enables Pacific people to understand mobility and place as simultaneously connected, and useful to discuss the experiences of global Pacific populations. ${ }^{11}$ Mobility in this situation, includes the mobility of ideas and of thought. 
Cosmopolitanism enables one to hold together a double complexity. ${ }^{12}$ This double complexity could be understood as a "self-conscious creolization of disciplinary skills or scholarly habitats" in one's research; this reveals "the complexities of the past, a mode that finds sufficiency not in reference to just one past figure but in the interweaving of references to many." 13 In a research context, then, cosmopolitan worlds require researchers to work hard to keep their complexity active and claim it as a "source of personal and professional identity." Cosmopolitan worlds are not only breeding grounds for transdisciplinarity; as well, because of the ways in which many ways of thinking and being are constantly colliding and crashing up against each other in any given locale, transdisciplinarity is vital. This transdisciplinary research is worth unpacking if we are to understand what people increasingly call Indigenous methodology. Transdisciplinary research is generally theorised outside the issue of Indigenous methodologies.

\section{Beyond Disciplinary Decadence: On Transdisciplinarity}

Philosopher Lewis Gordon argues that disciplinary decadence is the phenomenon of turning away from thought that engages with reality, and turning inward to one's own discipline. This turning in creates a mode of thinking where the discipline area becomes the world, and the "main concern is the proper administering of its rules, regulations, or, as Fanon argued, (selfdevouring) methods." 15 Gordon gives a range of examples of disciplinary decadence: it is "the literary scholar who criticises work in other disciplines as not literary. It is the sociologist who rejects other disciplines as not sociological. It is the historian who asserts history as the foundation of everything. It is the natural scientist that criticises the others for not being scientific. And it is also the philosopher who rejects all for not being properly philosophical."16 Following this argument, the obsession with the method being applied correctly leads to the discipline turning in on itself and eventually imploding.

One response to disciplinary decadence is interdisciplinarity. Pacific studies scholar Emalani Case contends that Pacific studies work is inherently interdisciplinary because it requires comparative analysis in order to account for Indigenous ways of knowing. Comparative analyses offer a means of understanding and acknowledging both similarities as well as cultural and historical specifities. Case positions herself in the tensions between disciplines, and sees this as a generative position for her work and her thinking. ${ }^{17}$ Black studies scholar Katherine McKittrick similarly advocates for interdisciplinarity, "because thinking and writing and imagining across a range of texts, disciplines, histories, and genres unsettles suffocating and dismal and insular racial logics." 18 In McKittrick's argument, when we bring together different sources, we have a way of looking at the analytics that lie beneath.

However, Gordon asserts that interdisciplinarity can still be susceptible to disciplinary decadence in the way it assumes disciplinary completeness. Instead, he argues that a more promising answer is transdisciplinarity, "where disciplines work through each other."19 Transdisciplinary scholarship is the notion of working across knowledge groups and discipline areas to understand and merge diverse perspectives. ${ }^{20}$ It is a relational research approach that deconstructs silos. The transdisciplinary researcher acknowledges the contestation at work for Indigenous scholarship, and works to "transcend the culture of the academy." 21 This is what Gordon names a "a teleological suspension of disciplinarity" that requires a willingness to go beyond disciplines to produce knowledge. This research approach requires an acceptance of "epistemological messiness" and an agreement that it can be productive. ${ }^{22}$ It is a process of assembling seemingly connected ideas, "fus[ing] and break[ing] apart how we know," pushing the work and thinking forward through "continuities and ruptures." 23 The value then exists in 
Pacific researchers as transdisciplinary actors, who question any stable foundations of knowledge we have at any given time, in pursuit of something more.

\section{Pacific Transdisciplinary Actors: On Theory}

Pacific researchers as transdisciplinary actors are the most fertile ground for the development of Pacific theory, theoretical thinking, and interventions that offer new ways of seeing and understanding the world around us. Decolonial theorist Linda Tuhiwai Smith writes that theory helps, at the very least, to make sense of one's reality, to make assumptions and predictions about the world we live in while also enabling Indigenous people to deal with contradictions and uncertainties, and provide space to plan our own resistances. ${ }^{24}$ Using lived experience to build theory works against the ways in which Indigenous people have been "oppressed by theory" and brings to the centre issues of one's own choosing, to be discussed amongst one's community. ${ }^{25}$

For people who have experienced incidences of trauma through processes of colonisation, it is common to not pass down stories. This silencing of narratives can be either conscious or a byproduct of trauma, in which family members conceal their trauma from their loved ones in an attempt to protect them from pain and emotional burden. ${ }^{26}$ However, considering the intergenerational trauma literature in regard to epigenetics, this silencing becomes an issue for subsequent generations who experience symptoms of intergenerational trauma but are locked out of knowing the full story. We know this to be important because self-narratives, whakapapa or gafa place us in our social worlds and offer frameworks through which we can relate to each other that offer a sense of "safety and security in our perception of the world."27 This kind of story work is theory. As Kwakwaka'wakw scholar Sarah Hunt explains, storytelling is a culturally nuanced way of making meaning. ${ }^{28}$ Within the context of Black studies, Katherine McKrittick contends that "as story, theory is cast as fictive knowledge and insists that the black imagination is necessary to analytical curiosity, and study." 29

Tuhiwai Smith writes about "researching back" alongside the Indigenous and feminist traditions of "writing back" or "talking back," all of which require a "knowing-ness of the colonizer' and a recovery of ourselves, and analysis of colonialism." ${ }^{30}$ This act of researching, writing, or talking back is something that needs constant reworking so that the impacts of imperialism and colonialism can be understood. ${ }^{31}$ For stories that exist outside of the colonial archive, "leaps of imagination" are required to connect disparate, fragmented pieces of a puzzle and to say that they belong together: this is decolonial work. ${ }^{32}$ Tuhiwai Smith defines decolonisation "as a process that engages with imperialism and colonialism at multiple levels. For researchers, one of those levels is concerned with having a more critical understanding of the underlying assumptions, motivations and values which inform research practices." 33 Normative research paradigms exclude or marginalise non-Western knowledge forms so that "non-Western/indigenous voices and epistemologies are silenced." 34 If Indigenous people do not theorise their own existence and realities, they may become complicit with colonialism. ${ }^{35}$ Decolonisation, then, becomes about understanding the impacts of imperialism within our thinking to recover ourselves as researchers. ${ }^{36}$

Decolonisation in this sense rejects the colonial narratives that one might have accepted as one's own. It is about "resurrecting your own stories, cherishing and valuing them for the power they can offer you." ${ }^{37}$ However, one must be careful to not freeze oneself in the past, thinking that decolonisation of the colonised world can be found exclusively in a past version of oneself, as "the things of the ancient past do not feed the stomachs of those who live today." 38 Rather, as political philosopher Fanon argues, there is a need to dismantle and reshape the 
contemporary world. ${ }^{39}$ For Chamorro scholar Michael Lujan Bevacqua, decolonisation "is about the present, and all that leads you away from this point is deceiving you." 40 Decolonisation, then, is about uncovering the conditions of the day and building new possibilities for the future.

When thinking about theory, Teresia Teaiwa's comments about contemporary art theory come to mind: there "simply weren't/aren't enough artists and critics to keep our movements honest." ${ }^{41}$ Commenting specifically in relation to Wendt and Hau'ofa's conceptualisations of Oceania, Teaiwa points out that "the primary consumers of Pacific arts continue to be outside of our natal or ethnic communities." ${ }^{2}$ Thus, within this context with little competition for audiences and their thinking, the result can be a lack of criticality. ${ }^{43}$ Theoretical approaches, then, can keep us honest, as well as leaving space for others to do the same.

Pacific transdisciplinary actors working on theory within the cosmopolitan context require, as Gordon writes, a willingness to go beyond discipline areas to produce knowledge. They require an acceptance of the messiness that comes, and a methodological approach to make sense of the productive and generative chaos. An acceptance of the chaos is vital not only in the production of knowledge but also in the capacity to develop theory that can hold the multifaceted and complex lived realities of Pacific people today. In my own transdisciplinary theorising, su'ifefiloi has been a methodological life raft when deeply immersed in the seas of thought that smash up against each other. In the following section I discuss the methodology of su'ifefiloi and the cosmopolitan intervention made into it, offering it as a culturally grounded methodological approach for transdisciplinary theorising.

\section{Su'ifefiloi: On Methodology}

Pacific research methodologies that both critique Western knowledge dominance in the university and offer new ways forward for Pacific researchers have been developed for decades now. They "provide a way for researchers to engage with and utilise Pacific ways of knowing and being," while also offering a "middle ground that is legible to both the academy and Pacific communities." 44 The necessary development of Pacific research methodologies speaks directly to Tuhiwai Smith's calls to research, write and talk back, as discussed in the previous section. Culturally rooted methodologies demonstrate how drawing on Indigenous concepts and stories can offer a theoretical grounding for knowledge creation. It is within this rich context of existing Pacific research methodologies that I think through su'ifefiloi: not as a blanket answer, but as the addition of one more possibility.

Su'ifefiloi can be broken down and translated as two key parts: su'i, which means to sew; and fefiloi, which means mixture. Together, su'ifefiloi describes the process of stitching together a mixture of elements: the process used in making ula or flower garlands. Thus, su'ifefiloi is a research methodology that combines diverse elements to create something new. ${ }^{45}$ The term su'ifefiloi was discussed as a methodology by Samoan novelist Sia Figiel while describing her approach to postcolonial literature. Figel states that "su'I means to sew, fefiloi means mixture, so it is a mixture of different flowers that we sew together. And then at the end, you hook them up, and they become an ula, a necklace of flowers." ${ }^{46}$ Therefore, su ifefiloi enables researchers to discover, analyse, and synthesise assorted data and methods so that each element of the research "can stand independently on its own and yet at the same time is connected to the others." ${ }^{\prime 47}$ micha cárdenas's concept of the stitch similarly discusses the productive process of joining separate elements to build new worlds. ${ }^{48}$ According to cárdenas, this offers a "basis for a theory of feminist making, which values the forms of knowledge practised daily by oppressed people as they make their lives in the face of violence." 49 
Figel uses the flowers pua and daffodils as metaphors for Pacific and Western thought that, through the methodology of su'ifefiloi, are able to come together in ways that are flexible yet autonomous. In Figel's own work we witness the su'ifefiloi in novels that tell uniquely Samoan stories through an expert understanding of literature. Leali'ifano Albert Refiti further developed Figel's articulation of su'ifefiloi for his own theoretical work in the discipline of architecture. Refiti writes that su'ifelioi leads to the production of new concepts through the refinement of Indigenous thought in the present. ${ }^{50}$ Through Refiti's work we are able to see how a su'ifefiloi of Samoan architecture, Western philosophy, spatial theory, and anthropology can be combined to offer a transdisciplinary theory of Samoan space.

In addition to the su'ifefiloi of ula making, the term also describes the "stringing of one song to another, like flowers to leaves, to form a long song." ${ }^{1}$ While in village settings this su'ifefiloi would play out in choirs with groups of people stringing one song to another, it could also be applied to the tradition of "fob mixes," which are remixes of songs and layered sounds burned onto CDs often accompanied by photoshop covers. ${ }^{52}$ This tradition has remained intact, though shifting onto music streaming sites like Soundcloud, and typified by people like DJ 651. While the form of su'ifefiloi changes, the underlying qualities remain the same each time, requiring "skill and sensibility to bring together a wide array of music and additional sound layers, to create something new - a mix built around a kind of vibe, event or genre of music." 53 $\mathrm{Su}$ 'ifefiloi in a music sense is literally a mode of remixing: each individual element remains recognisable (a Celine Dion sample, a reggae beat, with an overlay from a Samoan classic), but they are expertly combined so that as a whole su'ifefiloi each part makes sense together.

Curator and writer Legacy Russell writes about remixing as a way of "affirming our role in building new worlds," which requires both imagination and innovation. ${ }^{54}$ Remixing in this sense speaks to the need to "rearrange and repurpose by any means necessary." 55 For Russell, the colonial imaginary is material to be remixed, offering new material to be "reclaimed, rearranged, repurposed, and rebirthed toward an emancipatory enterprise." 56 The notion of remixing the material of dominant Eurocentric culture to create something new has been an enduring methodology for queer people, people of colour, and femme-identifying people; remixing here is a mode of survival and an act of self-determination. ${ }^{57}$ Cree Scholar Karyn Recollet offers the remix as an intervention into settler colonialism's disappearances and erasures. ${ }^{58}$ Recollet suggests that "remixing creates a future imaginary attentive to the past as it critiques the present, and ventures forward into the beyond." 59 For Recollet, the practice of sampling and mash-up is useful in a project that imagines future worlds.

Within my own doctoral research, su'ifefiloi enabled the combination of literature from many disciplinary areas (including Indigenous, decolonial and Black thought as well as Western philosophy) and methods like critical autoethnography, talanoa, and reparative reading to enable new thinking, leading to the development of the emerging theory: Moana cosmopolitan imaginaries. Rather than smoothing over disparate elements, theories and thoughts, the place in which they join together becomes a very important element. Tui Atua describes this as a cultural blend that supports unapologetic selves and gives equal time and respect to different cultural references, allowing each element to sit alongside others, "without apology." Su'ifefiloi allows an orientation toward what Boaventura de Sousa Santos calls "ecologies of knowledge," which highlight the multiplicity of different ways of knowing. ${ }^{61}$ Santos's ideal of knowledge is not to aim at "completeness or universality but rather to strive for a higher consciousness of incompleteness and pluriversality," or to "think of multiple forms of being contemporaneous." 62 Understanding the value of multiple ways of knowing contributes to a 
more diverse and profound understanding of the world, which then enables researchers to "cope with diversity and conflict in the absence of a general theory." 63

One of the most generative parts of su'ifefiloi is how it can already anticipate its own remaking, with elements being able to be unstitched and reused for new purposes. This mirrors the way in which su'ifefiloi takes from other places; it also acknowledges that its own parts can be taken. In this sense, it offers future research pathways for thinking yet to have happened. 
Cosmopolitan Interventions: On Ula Lole

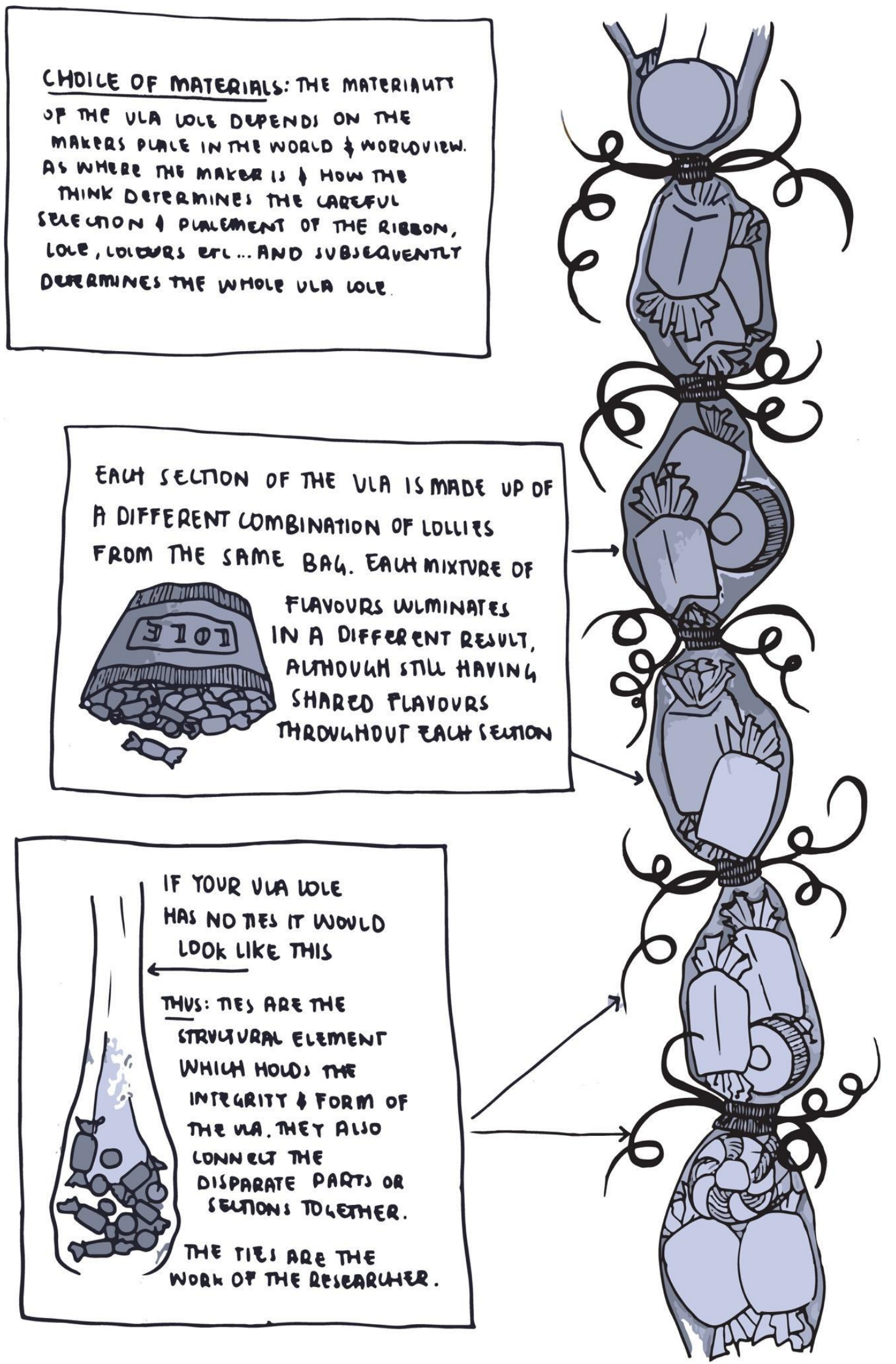

Figure 1. L. Lopesi, 2020, Design of Study—Su'ifefiloi ula Lole Adaptation 
It is important for Pacific researchers to remember that Pacific research is "just as vulnerable to hegemonic power plays as the dominant culture." ${ }^{\prime 64}$ One way this occurs is an over-reliance on clean metaphors and romantic visions of time past. In a journal article, Eseta Tualaulelei and Judy McFall-McCaffery write about a tendency in Pacific research methodologies to romanticise aspects of Pacific culture. They pinpoint a challenge for contemporary Pacific research approaches: "researchers might reach back into an idealised past that some argue never really existed." 65 This is coupled with the challenge of appropriating our own cultures and languages, including "metaphors of Samoan houses, canoe voyages, making garlands and quilting, which as already mentioned, may or may not be useful frames of reference for researchers who have no or limited lived experience of them." 66 This is something that is especially prescient within today's cosmopolitan worlds.

During my doctoral research, Māori artist and one of my supervisors Layne Waerea asked "What would your thesis look like if it was a drawing?" This prompt - meant to be a discussion point for the session - elicited deeper thinking about su'ifefiloi. Flower ula, while something I have received and seen people make, is not a process I engage in personally. Thus while I can understand and imply it theoretically, the knowledge is not empirical. However, I do make ula lole (lolly lei) for various occasions like my children's performances, graduations or celebrations of most kinds. While different in material, the purpose and process are the same as for flower garlands: they still require the methodology of su'ifefiloi. However, the key difference is that this is a process that I understand from a point of practice, and that also acknowledges the materiality of being Pacific within urban centres. In another supervision session, Leali'ifano Albert Refiti recounted how people, when they left from Aotearoa for their Moana homes, wore ula lole, and when they came back, they were wearing ula fugala'au (flower garlands). In this anecdote, the materiality of the ula lole speaks to the place of both the maker and the wearer of the ula, as the kind of ula one wears signals where they are leaving from and the materials of that environment. So leaving Aotearoa one wears an ula made from supermarket materials, and leaving Sāmoa the ula is made from fresh flowers.

The su'ifefiloi of the ula lole is made up of three key components: 1) the plastic wrap; 2) the lole themselves; and 3) the ribbon ties. The plastic wrap is the outer layer that holds everything in. In my doctoral research I envisioned that plastic wrap being the overarching theory that was being developed, the end result of the transdisciplinary actor. The different lole represent all of the disparate parts, methods, perspectives and knowledge enfolded by the theoretical envelope. They maintain their form and remain whole, but combine in particular ways within each section inside the plastic wrap. In each section of the ula lole, the mix of the lole is different. The ribbon ties give the ula lole structure; otherwise, all the lole would just fall through the plasticwrap casing. The ties are the hand of the transdisciplinary actor, they are the structuring and organisation of the research.

In an excerpt from my thesis, I wrote:

In my research, I think of this ula lole as held together by Glad Wrap, full of Starburst lollies and bound with bright shiny 2-dollar shop plastic ribbons. I envision my dining table where I would make it. These plastic and cheaply manufactured materials are unsustainable and the lollies are high in sugar, in contrast to the natural, tropical flowers of the homelands you might imagine when someone describes su'ifefiloi. However, the ula lole is connected to both an ancestral practice of making and gifting, and the materiality endemic to my place in the world. 
Su'ifefiloi is a methodology that already exists outside the world of research. So, while it is a useful tool within academic theorising, as uncovered in my doctoral research it is also a methodology for art making. The artists I had talanoa with felt comfortable using whatever media, concepts, theories or methods that were available to them in ways that remix and combine existing things to make something new. Through the talanoa it became clear that su'ifefiloi is itself a characteristic of the creative process. Rather than smoothing over disparate elements, theories and thoughts, the place where they join together, or the string of the ula, becomes a very important element. Artists enjoy being able to choose from a wide range of tools, knowledges, and technologies available to them, that enable a sense of play key to their art making.

Artist Emily Parr references Refiti's use of su'ifefiloi as a way to construct narratives that bring together diverse elements to "construct a sequence or build a surface area from many pieces, [establishing] an order without denying heterogeneity and discontinuity." ${ }^{67}$ Each part in the su'ifefiloi is whole in and of itself, meaning that it can stand alone; but when carefully selected and combined, the multiple elements produce something different. In this instance, su'ifefiloi was the methodology used in Parr's moving image work Moana Calling Me Home that led to Parr's imagining of her ancestral relations and specifically her 136upuna wāhine, or female ancestors. Within each of the six parts, Parr layers moving image, sound, and pürakau through narrative voiceover and drawing. Therefore, each of the six parts include a further sense of su'ifefiloi, making it central to the way Parr creates "from fragments of stories and moving images (the flowers), and strings them together to form the series (the necklace)."

\section{Final Thoughts}

$\mathrm{Su}$ 'ifefiloi is a generative methodology, which through the central tenet of combining is intended to generate new thinking and knowledge that always remains open to remixing and recombining. Thus, it is well suited for transdisciplinary theorising, a practice that requires continual visits and revisions to itself as new thought and ideas are acquired. Importantly it is a culturally grounded response to today's cosmopolitan world, helping move Pacific researchers beyond disciplinary decadence, bringing our own worlds into view as complicated and as having range.

$\mathrm{Su}$ 'ifefiloi is already applied within creative fields. Each of the references made to su'ifefiloi in this paper takes place within various creative forms: literature, art, and architecture. These areas are already transdisciplinary, comfortable with notions of experimentation and innovation where comparative analysis is highly valued. As acutely acknowledged by a reviewer for this paper, there are structural factors that may make transdisciplinary research for Pacific scholars more difficult that are important to acknowledge. These may include institutional racism, lack of capacity for transdisciplinary research, and racist attitudes toward Indigenous theories and methods. I hope in the future, especially in universities that claim transdisciplinarity, that su'ifefiloi may be of use to those struggling to traverse disciplinary decadence, or at the very least provide one example of a way forward.

Within a racist university system there is a valid fear of drawing from knowledge that has been used to oppress us. This can push researchers to the edge, creating an overreliance on golden pasts and returns to homelands. This tendency is totally understandable; however, it does little to reveal the complex and multilayered realities of today. Su'ifefiloi allows us to move beyond either/or binaries by encouraging careful selection and combinations of many parts. It offers malleability yet strength, allowing for disparate parts to combine and illuminate each other while remaining autonomous. Thus, I hope that su'ifefiloi can encourage us to move beyond a 
sceptical and overprotective approach to knowledge predicated on scarcity and fear, and to a place of reparative thought toward collective and abundant futures.

I humbly gift this ula lole not as a complete ula, but as the addition of a few more lole to an ula that was gifted to me. As I make the final tie in this su'ifefiloi, I tie it loosely, already anticipating the remaking and repurposing of it by researchers yet to come.

\footnotetext{
${ }^{1}$ I developed the ula lole metaphor in my $\mathrm{PhD}$ thesis, "Moana Cosmopolitan Imaginaries: Toward an Emerging Theory of Moana Art" (Auckland University of Technology, 2021). This was also used and further tested in a forthcoming journal article written by Seuta 'afili Patrick Thomsen, Lana Lopesi and Kevin Lujan Lee called "Contemporary Moana Mobilities: Upward Mobility and the Settler Colonial State," which has been accepted for publication by The Contemporary Pacific.

${ }^{2}$ Michael Christie, "Transdisciplinary Research and Aboriginal Knowledge," The Australian Journal of Indigenous Education 35 (2006): 82.

${ }^{3}$ Lewis Gordon, "Disciplinary Decadence and the Decolonization of Knowledge," Africa

Development 39, no. 1 (2014): 87.

${ }^{4}$ Lana Lopesi, "Moana Cosmopolitan Imaginaries: Toward an Emerging Theory of Moana Art" (PhD thesis, Auckland University of Technology, 2021), 179,

https://librarysearch.aut.ac.nz/vufind/Record/b3072669.

${ }^{5}$ James Clifford, Routes: Travel and Translation in the Late Twentieth Century (Cambridge: Harvard University Press, 1997), 255.

${ }^{6}$ Paul Gilroy, There Ain't No Black in the Union Jack (Oxfordshire: Routledge, 2002), 204.

${ }^{7}$ Clifford, Routes, 251.

${ }^{8}$ Vicente M. Diaz, "Oceania in the Plains: The Politics and Analytics of Transindigenous Resurgence in Chuukese Voyaging of Dakota Lands, Waters, and Skies in Mini Sota Makhoche," Pacific Studies 42, no. 1/2 (2019): 3 .

${ }^{9}$ Quoted in Peter Brunt, "Round Table: Thinking through Oceania Now," Reading Room: Liquid State 4 (2010): 103.

${ }^{10}$ Walter Mignolo, "Cosmopolitan Localism: A Decolonial Shifting of the Kantian's Legacies."

Localities 1 (2011): 22.

${ }^{11}$ See Paul Gilroy, The Black Atlantic (Cambridge: Harvard University Press, 1993); Clifford, Routes; James Clifford, Returns: Becoming Indigenous in the Twenty-first Century (Cambridge: Harvard University Press, 2012); Teresia Teaiwa, Searching for Nei Nim'anoa (Suva: Mana Publications, 1995); and Diaz, "Oceania in the Plains."

${ }^{12}$ Marylin Strathern, Partial Connections (Lanham: AltaMira Press, 2004), 20.

${ }^{13}$ Strathern, Partial Connections, 20.

${ }^{14}$ Strathern, Partial Connections, 20.

${ }^{15}$ Gordon, "Disciplinary Decadence," 86.

${ }^{16}$ Gordon, "Disciplinary Decadence," 86.

${ }^{17}$ Emalani Case, Everything Ancient Was Once New: Indigenous Persistence from Hawai 'i to Kahiki (Honolulu: University of Hawai'i Press, 2021), 5.

${ }^{18}$ Katherine McKittrick, Dear Science and Other Stories (Durham: Duke University Press, 2021), 4.

${ }^{19}$ Gordon, "Disciplinary Decadence," 87.

${ }^{20}$ Helen Moewaka Barnes et al., "Indigenous-led Environmental Research in Aotearoa New Zealand:

Beyond a Transdisciplinary Model for Best Practice, Empowerment and Action," AlterNative 17, no.

2 (2021): 307.

${ }^{21}$ Christie, "Transdisciplinary Research and Aboriginal Knowledge," 82.

${ }^{22}$ Christie, "Transdisciplinary Research and Aboriginal Knowledge," 82.

${ }^{23}$ McKittrick, Dear Science, 5.

${ }^{24}$ Linda Tuhiwai Smith, Decolonizing Methodologies: Research and Indigenous Peoples (Dunedin: Otago University Press, 2012), 87-88.
} 
${ }^{25}$ Tuhiwai Smith, Decolonizing Methodologies, 39.

${ }^{26}$ See Nora Buonagurio, "The Cycle Continues: The Effects of Intergenerational Trauma on the Sense of Self and the Healing Opportunities of Dance/Movement Therapy: A Literature Review" (MA thesis, Lesley University, 2020), https://digitalcommons.lesley.edu/expressive theses/280; and Angela Connolly, "Healing the Wounds of Our Fathers: Intergenerational Trauma, Memory, Symbolization and Narrative," Journal of Analytical Psychology 56, no. 5 (2011): 607-26.

${ }^{27}$ Buonagurio, "The Cycle Continues," 8.

${ }^{28}$ Sarah Hunt, "Ontologies of Indigeneity: The Politics of Embodying a Concept," Cultural Geographies 21, no. 1 (2014): 27.

${ }^{29}$ McKittrick, Dear Science, 8.

${ }^{30}$ Tuhiwai Smith, Decolonizing Methodologies, 8.

${ }^{31}$ Tuhiwai Smith, Decolonizing Methodologies, 25.

${ }^{32}$ Tuhiwai Smith, Decolonizing Methodologies, 323.

${ }^{33}$ Tuhiwai Smith, Decolonizing Methodologies, 58.

${ }^{34}$ Beth Blue Swadener and Kagendo Mutua, "Decolonizing Performances: Deconstructing the Global Postcolonial," in Handbook of Critical and Indigenous Methodologies, ed. Norman K. Denzin, Yvonna S. Lincoln, and Linda Tuhiwai Smith (Newbury Park: Sage, 2008), 5.

${ }^{35}$ Tuhiwai Smith, Decolonizing Methodologies, 72.

${ }^{36}$ Tuhiwai Smith, Decolonizing Methodologies, 63.

${ }^{37}$ Michael Lujan Bevacqua, "Their-Our Sea of Islands: Epeli Hau'ofa and Frantz Fanon,” Linq 37, no. 1 (2010): 84.

${ }^{38}$ Bevacqua, "Their-Our Sea of Islands," 87.

${ }^{39}$ Frantz Fanon, The Wretched of the Earth, trans. C. Farrington (New York: Grove Press, 1965).

${ }^{40}$ Bevacqua, "Their-Our Sea of Islands," 87.

${ }^{41}$ Quoted in Brunt, "Round Table," 90.

${ }^{42}$ Quoted in Brunt, "Round Table," 90.

${ }^{43}$ Quoted in Brunt, "Round Table," 90.

${ }^{44}$ Sereana Naepi, "Masi Methodology: Centring Pacific Women's Voices in Research," AlterNative 15, no. 3 (2019): 235.

${ }^{45}$ See Juniper Ellis, "Moving the Centre: An Interview with Sia Figiel," World Literature Written in English 37, no. 1-2 (1998): 69-79; Sia Figiel, "Pua and Daffodils: Weaving the Ula in Postcolonial Oceania," Journal of New Zealand and Pacific Studies 4, no. 1 (2016): 5-17; Albert L. Refiti, "Mavae and Tofiga: Spatial Exposition of the Samoan Cosmogony and Architecture" (doctoral thesis, Auckland University of Technology, 2014), https://openrepository.aut.ac.nz/handle/10292/9248; Amy Tielu, "Searching for the Digital Fāgogo: A Study of Indigenous Samoan Storytelling in Contemporary Aotearoa Digital Media (master's thesis, Auckland University of Technology, 2016), https://openrepository.aut.ac.nz/handle/10292/10417; and Aanoalii Rowena Fuluifaga, "O Feosofa'iga o le Vā: Samoan Women Negotiating Vā Relations in and around an Art Centre in Rural Samoa (master's thesis, Auckland University of Technology, 2017), https://openrepository.aut.ac.nz/ handle/10292/11014.

${ }^{46}$ Quoted in Ellis, "Moving the Centre: An Interview with Sia Figiel," 74.

${ }^{47}$ Ellis, "Moving the Centre: An Interview with Sia Figiel," 74.

${ }^{48}$ micha cárdenas, "Trans of Color Poetics: Stitching Bodies, Concepts, and Algorithms," The Scholar and Feminist Online 13, no. 3 (2016), https://sfonline.barnard.edu/traversing-technologies/michacardenas-trans-of-color-poetics-stitching-bodies-concepts-and-algorithms/.

${ }^{49}$ cárdenas, "Trans of Color Poetics."

${ }^{50}$ Refiti, "Mavae and Tofiga," 28.

${ }^{51}$ Figiel, "Pua and Daffodils," 6.

${ }^{52}$ Lopesi, "Moana Cosmopolitan Imaginaries."

${ }^{53}$ Lopesi, "Moana Cosmopolitan Imaginaries."

${ }^{54}$ Legacy Russell, Glitch Feminism: A Manifesto (New York, London: Verso, 2020), 143.

${ }^{55}$ Russell, Glitch Feminism, 143.

${ }^{56}$ Russell, Glitch Feminism, 131.

${ }^{57}$ Russell, Glitch Feminism, 131. 
${ }^{58}$ Karyn Recollet, "Gesturing Indigenous Futurities through the Remix," Dance Research Journal 48, no. 1 (2016): 91.

${ }^{59}$ Recollet, "Gesturing Indigenous Futurities through the Remix," 91.

${ }^{60}$ Tui Atua Tupua Tamasese Ta'isi Efi, Su'esu'e Manogi. In Search of Fragrance: Tui Atua Tupua

Tamasese Ta isi and the Samoan Indigenous Reference (Welllington: Huia, 2018), 9.

${ }^{61}$ Boaventura de Sousa Santos, The End of the Cognitive Empire: The Coming of Age of

Epistemologies of the South (Durham: Duke University Press, 2018): 77.

${ }^{62}$ Santos, The End of the Cognitive Empire, 275.

${ }^{63}$ Santos, The End of the Cognitive Empire, 213.

${ }^{64}$ Tamasailau M. Suaalii-Sauni, "Critiquing Pasifika Education at University," AlterNative 4 (2008): 22.

${ }^{65}$ Eseta Tualaulelei and Judy McFall-McCaffery, "The Pacific Research Paradigm: Opportunities and Challenges," MAI Journal: A New Zealand Journal of Indigenous Scholarship 8, vol. 2 (2019): 198.

${ }^{66}$ Tualaulelei and McFall-McCaffery, "The Pacific Research Paradigm," 198.

${ }^{67}$ Emily Parr, "The Ocean is Calling Me Home: Settler-Indigenous Relationships of Te Moananui a Kiwa" (master's thesis, Auckland University of Technology, 2020), 36.

${ }^{68}$ Parr, "The Ocean is Calling Me Home." 